\title{
УДК 376.33
}

ББК 74.5

\section{ОСОБЕННОСТИ ОВЛАДЕНИЯ СТИХОТВОРНЫМ ТЕКСТОМ МЛАДШИМИ ШКОЛЬНИКАМИ С НАРУШЕНИЕМ СЛУХА}

\author{
Е. Г. Речицкая, А. В. Дзюбань
}

Аннотация. Предлетол статьи является изучение особенностей овладения стихотворныли текстом младшили школьниками с нарушениел слуха. В статье представлен анализ програлмного и методического обеспечения прочесса обучения данной категории обучающихся, дается описание спроектированной многоколпонентной модели изучения и выявленной в результате проведенной эксперилентальной работы уровневой характеристики овладения стихотворныл текстол школьниками с нарушениел слуха в сравнении с норлально сльщащили детьли. Обосновывается необходилость специального колплексного подхода к изучению стихов в условиях инклюзивного обучения.

Ключевые слова: особенности овладения стихотворныл текстол, слысл текста, уровни и средства речевой выразительности, лногоколпонентная модель, характеристика динамических особенностей, продуктивность заполинания, учащиеся с нарушениел слуха, особые образовательные потребности, инклюзивное обучение.

\section{FEATURES OF MASTERING A POETIC TEXT BY THE YOUNGER PUPILS WITH HEARING IMPAIRMENT}

\section{E. G. Rechitskaya, A. V. Dziuban}

\begin{abstract}
The article analyzes the peculiarities of mastering the poetic text by younger schoolchildren with hearing impairment. The article presents an analysis of the software and methodological support of the learning process of this category of students, describes the designed multicomponent model of training and the level characteristics of learning of a poetic text identified by hearing impaired students as compared to normal hearing children as a result of the conducted experimental work. The necessity of a special integrated approach to the study of poetry in the context of inclusive education is substantiated.
\end{abstract}

Keywords: features of mastering a poetic text, the meaning of the text, levels and means of speech expressiveness, multicomponent model, characteristic of dynamic features, productivity of memorizing, pupils with hearing impairment, special educational needs, inclusive education. 
П1 оэзия является высшим выражением духовной культуры любого народа и имеет особое значение для формирования эмоций, чувств, эстетического вкуса, гуманистических идеалов, способствует развитию творческого потенциала, особенно в период развития и становления личности. Стихотворные произведения учат читателя вглядываться в чувства, эмоции других людей и самого себя, тоньше и глубже воспринимать и осознавать окружающий мир. Чтение, анализ, интерпретация поэтических текстов стимулируют познавательную активность и мыслительную деятельность человека, влияют на развитие и формирование речевых навыков и умений, формируют «языковое чутье». Таким образом, умственное, речевое, эстетическое и эмоциональное развитие невозможно без использования литературного, в том числе поэтического творчества, что, в свою очередь, способствует становлению гармоничной, творчески мыслящей личности, имеющей «личностные смыслы, личностные установки» и гражданскую ответственность.

Вышесказанное играет особую роль при выборе методов и способов воспитания, обучения и развития ребенка с особенностями психофизического и речевого развития, в частности, ребенка с нарушением слуха как целостной, гармонично развитой личности.

Целью нашего исследования стало выявление особенностей овладения стихотворным текстом младшими школьниками с нарушением слуха. Исследование проводилось на базе МБОУ СШ № 5 г. Архангельска и МБОУ СОШ № 21 г. Северодвинска. К процессу исследования было привлечено 34 обучающихся с нарушением слуха из 2-го и 3-го классов.

Так как нарушения в развитии могут привести к выпадению из культурно и социально обусловленного образовательного пространства [1], соответственно одной из специальных задач обучения является введение ребенка с нарушением слуха в социум и культуру через обходные пути, за- действовав компенсаторные возможности и применяя индивидуальный, личностноориентированный подход. При этом важно, используя специальные методы, приемы, средства обучения, обеспечить особую временную и пространственную организацию образовательной среды как в рамках самой образовательной организации, так и за ее пределами [2], что предполагает учет особых образовательных потребностей обучающихся.

Особые образовательные потребности должны иметь отражение в первую очередь в программе образовательного стандарта для школьников с нарушением слуха, в связи с чем нами было проанализировано содержание федеральных государственных образовательных стандартов (ФГОС) для младших школьников с нарушением слуха. Проведенный анализ позволил нам сделать следующие выводы:

1. Учащиеся начальных классов с нарушением слуха общеобразовательной школы обучаются в условиях инклюзии по адаптированной общеобразовательной программе начального общего образования для слабослышащих и позднооглохших обучающихся - первый вариант (А), согласованный с ФГОС для обучающихся с ограниченными возможностями развития (ОВ3) (в редакции от 03.04.2015).

2. Адаптированная программа направлена на формирование у обучающихся с нарушением слуха универсальных учебных действий. Кроме того, она подразумевает специальную, коррекционно-развивающую и психолого-педагогическую поддержку коллектива учителей, родителей, детского коллектива и самого обучающегося. Вместе с тем первый вариант этой программы не предусматривает раскрытия содержания каждой образовательной области, включая коррекционно-развивающую область и внеурочную деятельность, как это сделано в вариантах два (B), три (C) и четыре (D) - для глухих детей.

3 Согласно программным требованиям в обучении слабослышащих детей, предусмотрено использование базовых учебни- 
ков для сверстников с нормальным слухом, к которым с учетом особых образовательных потребностей должны прилагаться специальные дидактические материалы, рабочие тетради и прочее, но в наличии их сегодня нет. Только при реализации программы коррекционной работы используются специальные учебники по обучению произношению и развитию слухового восприятия, формированию грамматического строя речи и развитию речи.

Все это ставит младших школьников с нарушением слуха в неравные условия по сравнению с нормально слышащими сверстниками в рамках инклюзивного обучения, что может привести к рискам при требовании необходимости усвоения общеобразовательной программы в полном объеме, а также спровоцировать негативное отношение к поэтическому творчеству в целом, к чтению и заучиванию стихотворных текстов, в частности, вследствие их сложности для понимания детьми с нарушениями слуха и речи. А это, безусловно, отразится на эмоционально-чувственном, творческом, эстетическом и речевом развитии школьников с нарушением слуха [3].

Далее нами был проведен анализ имеющихся в литературе методик выявления особенностей овладения стихотворным текстом младшими школьниками, который обнаружил потребность в их модификации и конструировании специальной методики для детей с нарушением слуха младшего школьного возраста.

Для начала обозначим, что мы понимаем под понятием «овладение стихотворным текстом». На наш взгляд, оно включает в себя два следующих процесса: художественное восприятие стихотворных текстов и их художественное воспроизведение.

Художественное восприятие стихотворных текстов - это творческий процесс, включающий понимание художественносмысловой и эстетической стороны произведения, а также чувственную окрашенность воспринятого, соучастие, сопереживание авторскому восприятию.
Художественное воспроизведение стихотворных текстов - это связная последовательная передача содержания стихотворного текста в выразительной устной форме. В передаче активно участвуют мышление ребенка, его память, воображение, эстетическое восприятие содержания и формы произведения, понимание конкретного содержания, предметного плана текста, а также заключенных в нем разнообразных смыслов и смысловых связей [3], авторского замысла.

Поэтому для выявления особенностей овладения стихотворным текстом детьми младшего школьного возраста нами были выделены следующие критерии: понимание смысла стихотворного текста, уровень сформированности средств речевой выразительности, скорость запоминания стихотворного текста.

Для выявления способности понимать смысл стихотворного текста ребенку с нарушением слуха предлагалось внимательно прослушать выразительное и эмоциональное прочтение четверостишия педагогом, затем самостоятельно прочитать стихотворение и выполнить рисунок к тексту. При этом не следовало уточнять понимание учеником значений слов или толковать смысл четверостишия. Стихотворение считалось понятым, если иллюстрация соответствовала содержанию, или не понятым, если иллюстрация не соответствовала содержанию или отражала только частичное понимание отдельных слов и фраз четверостишия. Это составило первую часть предлагаемой нами модели диагностики.

Для исследования уровня сформированности средств речевой выразительности были использованы рекомендации по обследованию просодической стороны речи у дошкольников со стертой дизартрией (Е. Ф. Архипова) [4]. Так нами была сконструирована вторая часть модели изучения особенностей овладения стихотворным текстом детьми с нарушением слуха младшего школьного возраста, включающая пять заданий, которые позволили нам выявить особенности основных компонентов, 
наиболее значимых при воспроизведении стихотворений, а именно: ритма, логического ударения и пауз, силы и высоты голоса, интонации.

Скорость запоминания стихотворного текста (третья часть модели) оценивалась по трем критериям: характеристика динамических особенностей процесса запоминания, определение продуктивности запоминания четверостишия (методика Р. С. Немова [5]) и оценивание способа запоминания семантически доступного программного стихотворения. Суть оценивания способа запоминания стихотворного текста заключалась в следующем: школьник слушал выразительное и эмоциональное чтение исследователя, затем самостоятельно его прочитывал вслух такое количество раз, которое считал необходимым для запоминания. Оценивалось следующее: сумел или не сумел ученик рассказать стихотворение наизусть; какое количество прочтений ему требовалось для запоминания; каким способом он при этом пользовался: неоднократно прочитывал текст целиком, запоминал по предложениям, запоминал построчно; замечал и исправлял допущенные ошибки или нет; принимал или не принимал помощь взрослого; наличие аграмматизмов, замен и перестановок слов в ходе рассказывания.

Таким образом, сконструированная нами модель изучения особенностей овла- дения стихотворным текстом младшими школьниками с нарушением слуха включала 3 части.

Остановимся на полученных результатах. Изучение способности младших школьников понимать смысл стихотворного текста («Жгуч мороз трескучий, на дворе темно. Серебристый иней запушил окно», И. Никитин) показало, что у $60 \%$ учащихся с нормальным слухом иллюстрация соответствовала содержанию стихотворения, а у $40 \%$ иллюстрация отображала только один из элементов содержания, то есть понимания смысла отрывка как единого целого у них не было.

Среди учеников с нарушенным слухом лишь 28\% детей поняли содержание стихотворения после выразительного прочтения его экспериментатором и самостоятельного прочтения ребенком: сделанные ими иллюстрации соответствовали содержанию текста. Большинство же школьников с нарушением слуха (72\%) содержания стихотворения не поняли, при этом у 68\% из них рисунок не был даже близок к содержанию текста (изображался летний пейзаж с домом, не имеющий никакого отношения к предложенному отрывку) или соответствовал ему лишь частично у $4 \%$ (имелось изображение окна с зимним узором на нем), также у 9\% учеников встречались отвлеченные добавления к рисунку, связанные с новогодней тематикой (рис. 1).

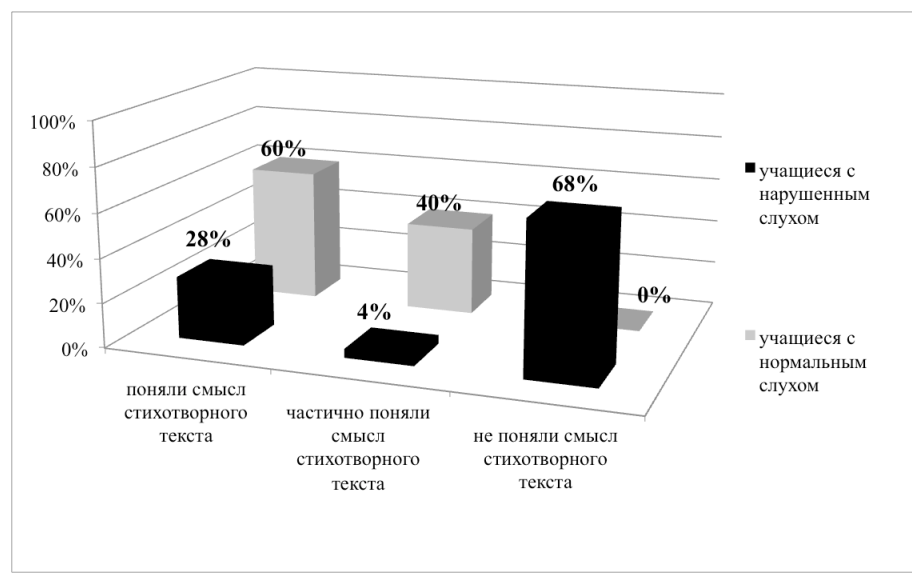

Puc 1. Диаграмма способности понимать смысл стихотворного текста 
Исследование сформированности средств речевой выразительности младших школьников с нарушением слуха позволило нам сделать вывод о том, что учащиеся младших классов с нарушением слуха имеют специфические особенности интонационной стороны речи, которые проявляются в недостаточно сформированном умении воспроизводить ритмический рисунок текста, правильно расставлять логическое ударение и делать логические паузы во фразе, изменять мелодику произнесенной фразы и тембровую окраску голоса, что будет отражаться на понимании и воспроизведении стихотворных текстов (рис. 2).

Далее рассмотрим особенности процессов запоминания стихотворного текста младших школьников, по результатам исследования динамичности и продуктивности заучивания. Дети, не имеющие нарушений слуха, все имели отличную оценку продуктивности и высокий уровень динамичности запоминания, так как от повторения к повторению их результаты улучшались - кривая плавно поднимается вверх, также все дети данной категории воспроизвели предложенное им для заучивания четверостишие с первого раза.

Среди учеников с нарушением слуха отличную оценку динамичности заучивания имели лишь $29 \%$ обучающихся, с каждым повторением они правильно удержи- вали в памяти все больше слов (рис. 3, а). Динамичность заучивания оценена удовлетворительно у $17 \%$ младших школьников с нарушением слуха, так как у них от повторения к повторению результаты не ухудшались, но оставались на прежнем уровне (рис. 3, 6). А 54\% детей получили неудовлетворительную оценку, их результаты от повторения к повторению то улучшались, то ухудшались, что свидетельствует о нединамичном процессе заучивания (рис. 3, в). Только $14 \%$ учеников с нарушением слуха продемонстрировали высокий уровень продуктивности запоминания: они сумели правильно воспроизвести четверостишие за шесть повторений. Большинство младших школьников с нарушением слуха (86\%) имеют средний уровень продуктивности запоминания, они за шесть повторений так и не смогли запомнить все слова пробы.

Нединамичный и средне-продуктивный процессы запоминания у большинства школьников с нарушением слуха подтверждает тот факт, что лишь одна ученица смогла воспроизвести предложенное четверостишие с первого раза. $21 \%$ учеников воспроизвели стихотворный текст со второй попытки, причем заучивание было механическим, дети воспроизводили стихотворение неэмоционально, монотонно, без интонаций. Большинство учеников (59\%) воспроизвели стихотворение с 4-5 раза, допу-

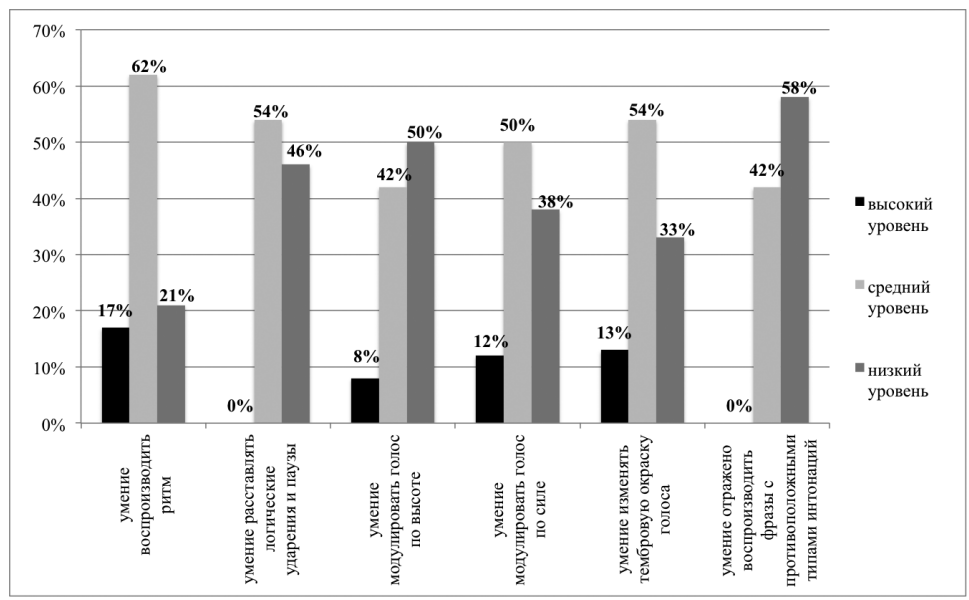

Puc 2. Гистограмма сформированности средств речевой выразительности 


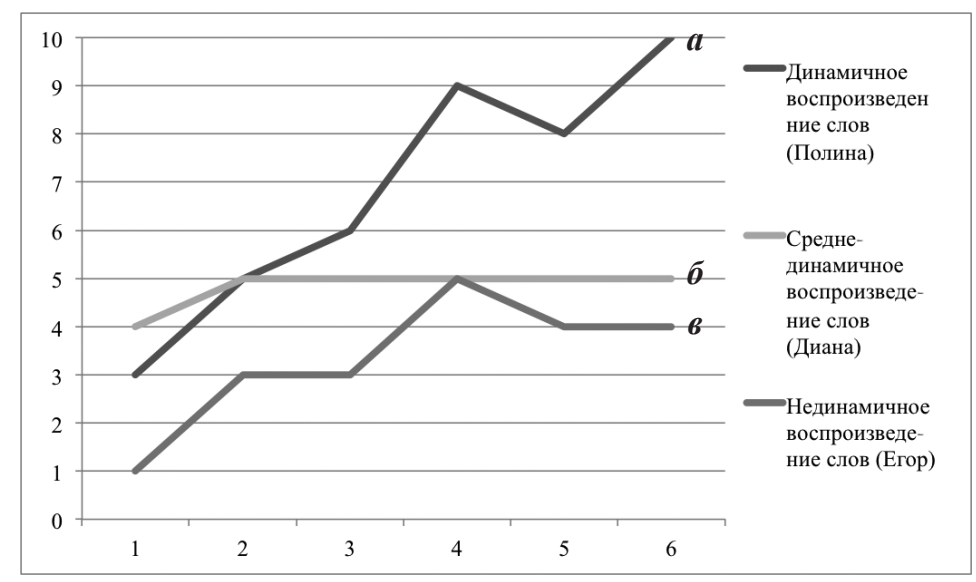

Puc. 3. Динамические особенности процесса заучивания

ская при этом ошибки в виде перестановки слов, опускания окончаний, из-за чего разрушалась ритмическая структура стихотворения. $17 \%$ школьников так и не смогли запомнить и рассказать стихотворение от начала и до конца.

Резюмируя, можно сделать следующие выводы об особенностях овладении стихотворным текстом младшими школьниками с нарушением слуха:

1. Большинство учеников с нарушением слуха сразу не понимают содержания стихотворного отрывка после выразительного прочтения его учителем и самостоятельного прочтения, а значит, оказываются не до конца вовлеченными в урок при работе со стихотворением.

2. У всех младших школьников, имеющих нарушение слуха, интонационная сторона речи находится на низком или среднем уровне, следовательно, учащиеся плохо понимают или совсем не понимают эмоционально-выразительную составляющую стихотворного произведения.

3. Школьники с нарушениями слуха испытывают затруднения при запоминании стихотворных текстов, процесс заучивания у них характеризуется как средне-динамичный и нединамичный.
Проведенное исследование свидетельствует о том, что учащиеся младших классов с нарушением слуха имеют сложности в овладении стихотворными текстами из-за особенностей их психофизического развития и развития их речемыслительной деятельности вследствие нарушения слуха. При этом методика работы с поэтическими произведениями в условиях инклюзивного обучения не учитывает особенностей развития детей с нарушением слуха, а значит, не ориентирована на их особые образовательные потребности и не предусматривает использования специальных технологий обучения, специфических методов и приемов при ознакомлении со стихотворными произведениями. Методика, как правило, основана на вербальном общении, заключающемся в вопросно-ответной форме работы над содержанием стихотворений [3].

Учебник литературного чтения ${ }^{1}$ для общеобразовательных учреждений также ориентирован только на обучающихся с сохранным слухом.

Результаты исследования позволяют сделать следующее заключение. Поэтические произведения оказывают позитивное воздействие на чувства и эмоции, стимулируют мыслительную деятельность, способ-

1 Литературное чтение 2 класс: учеб. для общеобразовательных учреждений с аудиоприложением на электронном носителе в двух частях / Л. Ф. Климанова, В. Г. Горецкий, М. В. Голованова, Л. А. Виноградская, М. В. Бойкина. М.: Просвещение, 2013. 
ствуют развитию творческого потенциала, формируют эстетический вкус. Вместе с тем у младших школьников с нарушением слуха по сравнению с нормотипическими показателями выявлены особенности овладения стихотворным текстом, которые обусловлены специфическими особенностями нарушенного психического развития. По мнению В. И. Лубовского, к этим особенностям для всех типов дизонтогенеза следует отнести замедленную в сравнении с нормой скорость приема, переработки и воспроизведения информации (то есть замедленность сенсорно-перцептивных процессов), меньший объем сохраняемой информации (то есть более низкую эффективность процессов памяти), более низкую работоспособность [6]. При этом возможности запечатления и сохранения стихотворного текста относятся к когнитивным процессам, а нарушения сосредоточения, удержание внимания, познавательная мотивация, внутренние переживания, душевное состояние, которое вызывают поэтиче- ские произведения, характеризуют эмоционально-волевую деятельность [7; 8].

Таким образом, можно считать, что выявленные в экспериментальном исследовании особенности носят «генеральный характер» (В. И. Лубовский). Они действуют при нарушенном слухе вследствие возрастной недостаточности психических и психофизиологических функций, и прежде всего вследствие отставания в развитии речемыслительной деятельности, памяти и эмоционально-волевой сферы. Как следствие действия этих факторов, мы и наблюдаем выявленные нами особенности детей, имеющих нарушения слуха, в восприятии, понимании, сохранении и воспроизведении стихов в сравнении с нормой, что свидетельствует о необходимости разработки специального комплексного подхода при изучении поэтических произведений детьми с нарушением слуха младшего школьного возраста для получения качественных образовательных результатов в условиях инклюзивного обучения.

\section{СПИСОК ИСТОЧНИКОВ И ЛИТЕРАТУРЫ}

1. Кукушкина О. И. Информационные технологии в контексте отечественной традиции специального образования: моногр. - М.: Полиграф Сервис, 2005. - 327 с.

2. Единая концепция специального федерального государственного стандарта для детей с ограниченными возможностями здоровья: основные положения / Н. Н. Малофеев, О. С. Никольская, О. И. Кукушкина, Е. Л. Гончарова // Альманах Института коррекционной педагогики. - 2009. - № 13. - URL: https://alldef.ru/ru/articles/ almanah-13/edinaja-koncepcija-specialnogo-federalnogo-gosudarstvennogo (дата обращения: 22.10.2018).

3. Дзюбань A. B. Теоретические основы проблемы овладения стихотворным текстом младшими школьниками с нарушением слуха в условиях инклюзивного обучения // Наука и школа. - 2018. - № 5. - С. 108-114.

4. Архипова Е. Ф. Стертая дизартрия у детей. - М.: АСТ: Астрель: Хранитель, 2007. - 319 с.

5. Немов Р. С. Психология. Кн. 3: Психодиагностика. Введение в научное психологическое исследование с элементами математической статистики. - М.: Владос, 2016. - 631 с.

6. Лубовский В. И. Особые образовательные потребности // Психологическая наука и образование. - 2013. - № 5. - С. 61-66.

7. Речицкая Е. Г., Кулигина Т. Ю. Развитие эмоционально-оценочной лексики у детей с нарушением слуха младшего школьного возраста: моногр. - Saarbrcken: Lap Lambert, 2014. - $158 \mathrm{c}$.

8. Речиикая Е. Г., Кулигина Т. Ю. Развитие эмоциональной сферы детей с нарушенным и сохранным слухом: метод. пособие. - М.: Книголюб, 2006. - 208 с. (Развитие и коррекция). 


\section{REFERENCES}

1. Kukushkina O. I. Informatsionnye tekhnologii v kontekste otechestvennoy traditsii spetsialnogo obrazovaniya: monogr. Moscow: Poligraf Servis, 2005. 327 p.

2. Malofeev N. N., Nikolskaya O. S., Kukushkina O. I., Goncharova E. L. Edinaya kontseptsiya spetsialnogo federalnogo gosudarstvennogo standarta dlya detey s ogranichennymi vozmozhnostyami zdorovya: osnovnye polozheniya. Almanakh Instituta korrektsionnoy pedagogiki. 2009, No. 13. Available at: https://alldef.ru/ru/articles/almanah-13/ edinaja-koncepcija-specialnogo-federalnogo-gosudarstvennogo (accessed: 22.10.2018).

3. Dzyuban A. V. Teoreticheskie osnovy problemy ovladeniya stikhotvornym tekstom mladshimi shkolnikami s narusheniem slukha v usloviyakh inklyuzivnogo obucheniya. Nauka i shkola. 2018, No. 5, pp. 108-114.

4. Arkhipova E. F. Stertaya dizartriya u detey. Moscow: AST: Astrel: Khranitel, 2007. 319 p.

5. Nemov R. S. Psikhologiya. Vol. 3: Psikhodiagnostika. Vvedenie v nauchnoe psikhologicheskoe issledovanie s elementami matematicheskoy statistiki. Moscow: Vlados, 2016. $631 \mathrm{p}$.

6. Lubovskiy V. I. Osobye obrazovatelnye potrebnosti. Psikhologicheskaya nauka i obrazovanie. 2013, No. 5, pp. 61-66.

7. Rechitskaya E. G., Kuligina T. Yu. Razvitie emotsionalno-otsenochnoy leksiki u detey s narusheniem slukha mladshego shkolnogo vozrasta: monogr. Saarbrcken: Lap Lambert, 2014. 158 p.

8. Rechitskaya E. G., Kuligina T. Yu. Razvitie emotsionalnoy sfery detey s narushennym $i$ sokhrannym slukhom: metod. posobie. Moscow: Knigolyub, 2006. 208 p. (Razvitie i korrektsiya).

Речицкая Екатерина Григорьевна, кандидат педагогических наук, профессор Кафедры инклюзивного образования и сурдопедагогики Московского педагогического университета

e-mail: elisvesta@mail.ru

Rechitskaya Ekaterina G., PhD in Education, Professor, Inclusive education and deaf and dumb pedagogy Department, Moscow Pedagogical State University

e-mail: elisvesta@mail.ru

Дзюбань Александра Владимировна, ассистент кафедры специальной педагогики и психологии Высшей школы психологии, педагогики и физической культуры Северного Арктического федерального университета имени М. В. Ломоносова; аспирант Кафедры инклюзивного образования и сурдопедагогики Дефектологического факультета Института детства Московского педагогического государственного университета

e-mail: a.dzyuban@narfu.ru

Dziuban Aleksandra V., Assistant, Special Pedagogy and Psychology Department, Higher School of Psychology, Pedagogy and Physical Culture, M.V. Lomonosov Northern (Arctic) Federal University, Postgraduate student, Inclusive education and deaf and dumb pedagogy Department, Defectology Faculty, Institute of Childhood, Moscow Pedagogical State University

e-mail: a.dzyuban@narfu.ru

Статья поступила в редакцию 07.03.2019

The article was received on 07.03.2019 